\title{
Microstructure and precipitated phase in the thermo-mechanically affected zone of friction stir welded joint for 2024 aluminium alloy
}

\author{
Peng Liu $^{1 *}$, Guoliang Liu $^{2}$, Yan Deng ${ }^{3}$, Jianing Li $^{1}$, Cainian Jing $^{1}$, Keyun Feng ${ }^{1}$ \\ ${ }^{1}$ School of Materials Science and Engineering, Shandong Jianzhu University, Jinan 250101, P. R. China \\ ${ }^{2}$ Sino-India Computer Software Institute, Weifang University of Science and Technology, Weifang 262700, P. R. China \\ ${ }^{3}$ Jinan Semiconductor Device Insitute, Jinan 250041, P. R. China
}

Received 30 December 2014, received in revised form 24 May 2015, accepted 4 December 2015

\begin{abstract}
The 2024 aluminium alloy sheets in the T4 temper were welded successfully by the friction stir welding techniques. The AlCuMg ( $U$-phase) of metastable precipitates was found to exist in the thermo-mechanically affected zone using TEM analysis. Moreover, the $U$-phase is likely to induce the formation of two distinct microhardness minima in the stir zone of FSW weld. The $\mathrm{AlCu}_{3}$ and $\mathrm{Cu}_{2} \mathrm{Mg}$ particles were precipitated on the grain boundary of the thermomechanically affected zone and in the weld nugget region, respectively.
\end{abstract}

K e y w ords: aluminium alloys, friction stir welding, microstructure, transmission electron microscopy

\section{Introduction}

Aluminium and aluminium alloys are widely used to obtain components for aerospace applications with high specific strength. However, the precipitation hardenable $2 \times \times \times(\mathrm{Al}-\mathrm{Cu}-\mathrm{Mg}), 6 \times \times \times(\mathrm{Al}-\mathrm{Mg}-\mathrm{Si})$ and $7 \times \times \times(\mathrm{Al}-\mathrm{Zn})$ aluminium alloys were considered before as "unweldable" by fusion process [1], which are often difficult to be fusion welded without hot cracking, porosity or distortion.

Friction stir welding (FSW) is a recent method of joining materials, patented by the Welding Institute (TWI) in 1991 [2]. This process constitutes a development of the classical friction welding methods. Usually, in the FSW process, no melt of the joining parts occurs and the weld forms through solid-state plastic flow at elevated temperature [3]. Therefore, FSW can assure the absence of porosity, hot cracking and rather a large distortion that are typical defects of the fusion processes [4]. Moreover, it assures the possibility to operate in all positions with no protective gas. At present, several $\mathrm{Al}$ alloys of traditional considered unweldable have been successfully welded by FSW [5, 6].

In $2 \times \times \times$ series alloys, copper is the primary hard- ening element. Magnesium is often added to increase the natural ageing and the maximum strength. The alloys obtain their very high strength by precipitation of the phases $\mathrm{Al}_{2} \mathrm{Cu}$ ( $\theta$-phase) and/or $\mathrm{Al}_{2} \mathrm{CuMg}(S$ or $S^{\prime}$-phase). The variation of microhardness in the stir zone is also associated with the kind and shape of precipitates [7, 8]. Jones et al. [9] analysed the correlation between microstructure and microhardness of FSW joint for AA2024-T351 aluminium alloy by using transmission electron microscopy (TEM). It was found that the very fine $S$ precipitates existed between the thermo-mechanically affected zone (TMAZ) and heat-affected zone (HAZ). The hardness minimum close to the TMAZ was the result of the coarsening and overageing of the $S$-phase occurring during the thermal cycle. The hardness minimum was thought to be due to the dissolution of the very fine $S$-phase occurring towards the outer edge of HAZ. The hardness maximum between these two minima was seen to be due to the presence of the very fine $S$-phase. Recent investigations by Genevois and co-workers [10, 11] reported precipitation and mechanical behaviour of AA2024 aluminium alloys under the T351 and T6 tempers. The initial precipitation is composed entirely of GP zone. In the HAZ, the increase of temperature

*Corresponding author: e-mail address: liupeng1286@163.com 
Table 1. Chemical composition and thermo-physical performance of 2024 aluminium alloys

\begin{tabular}{lcccccc}
\hline \multirow{2}{*}{ Materials } & \multicolumn{5}{c}{ Chemical composition (wt.\%) } \\
\cline { 2 - 7 } & $\mathrm{Cu}$ & $\mathrm{Mg}$ & $\mathrm{Si}$ & $\mathrm{Fe}$ & $\mathrm{Mn}$ & $\mathrm{other}$ \\
\hline $\mathrm{Al} 2024$ & $3.8-4.9$ & $1.2-1.8$ & 0.5 & 0.5 & 0.30 .9 & $\mathrm{Al}$ \\
\hline
\end{tabular}

induces the dissolution of GP zone, and the latter is replaced by fine $S^{\prime}(S)$ precipitates. These particles grow with higher temperature, inducing a hardness fall in the HAZ/TMAZ.

In this paper, the microstructure and microhardness distribution of the weld for 2024-T4 FSW weld were observed and analysed by an optical microscopy and microhardness tester. Moreover, the grain morphology and new precipitated phases in the WN region and TMAZ were observed and analysed using TEM. This is helpful for the further study of the relation between phase constitution and joints performance in friction stir welded aluminium alloys.

\section{Experimental}

The examined joined sheets of 2024-T4 aluminium alloys had dimensions of $150 \mathrm{~mm} \times 60 \mathrm{~mm} \times 3 \mathrm{~mm}$. The chemical composition of the test material is shown in Table 1. Two $3 \mathrm{~mm}$ thick sheets were butt welded, using the friction stir welding technique. The welding direction was parallel to the rolling direction of the sheets. The tool rotational speed and travel speed were $475 \mathrm{rpm}$ and $300 \mathrm{~mm} \mathrm{~min}^{-1}$, respectively.

The 2024-T4 aluminium alloy sheets were welded successfully by FSW. A series of specimens were cut, and then these specimens were made into metallographic samples. The samples were etched using mixed solution $1.0 \% \mathrm{HF}+1.5 \% \mathrm{HCl}+2.5 \% \mathrm{HNO}_{3}+95 \%$ $\mathrm{H}_{2} \mathrm{O}$. The microhardness tester of the MH-3 type was used to acquire microhardness distribution across the facing polished cross section with $100 \mathrm{~g}$ loading and a load time of $10 \mathrm{~s}$. Then, the sample was cut into foils by linear cutting machine. For TEM investigations, thin foils were prepared using double jet electro-polishing, using a solution containing $\mathrm{HNO}_{3}$ and $\mathrm{CH}_{3} \mathrm{OH}(1: 3)$ at $18 \mathrm{~V}$ and $-20^{\circ} \mathrm{C}$. The microstructural investigation was carried out on a JEOL 2011 FX instrument with a W-filament operated at $200 \mathrm{kV}$.

\section{Results and analysis}

\subsection{Microhardness distribution and grain size}

The microstructure and microhardness distribution of cross-section for the FSW joint are shown in

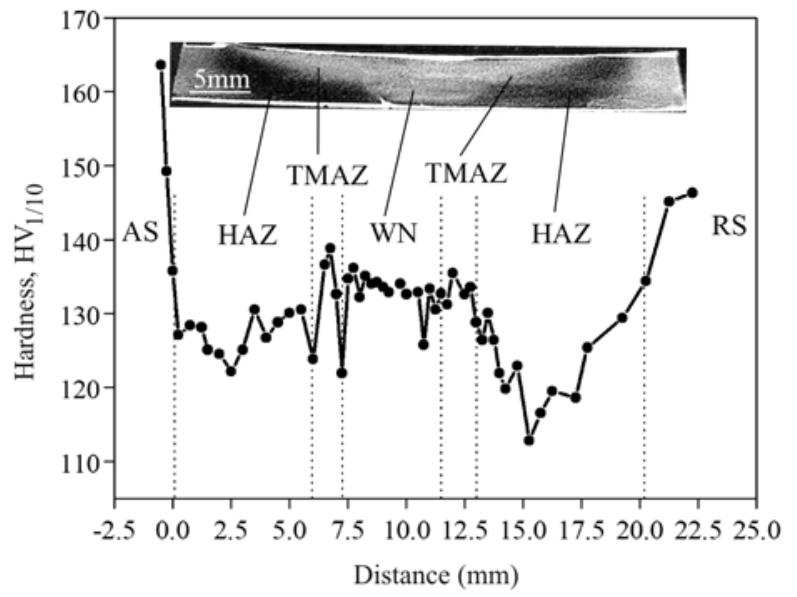

Fig. 1. Cross-section and microhardness distribution in the stir zone of FSW 2024 aluminium alloys.

Fig. 1. The grain morphology in the different weld regions is shown in Fig. 2.

The weld of FSW joint is composed of three regions, namely HAZ, TMAZ, and WN. According to Fig. 1, the hardness distribution is related to the distribution of the cross-section structure of FSW joint. The microhardness in the weld decreases from the base metal toward the weld, then begins to increase toward the centre of the weld (stir zone). This phenomenon was induced by the thermal cycling of FSW $[12,13]$. The microhardness of the weld continues to increase to a maximum value (HV 133-138) across the TMAZ, and then the microhardness experiences an abrupt drop of $\mathrm{HV}$ 6-8 inside the WN region. At last, the lower microhardness is distributed along the WN region. According to Fig. 1, it was found to contain two distinct hardness minima on HAZ/TMAZ and TMAZ/WN. This is supposed to be the presence of precipitates in the TMAZ [9-11]. Moreover, some precipitates were dissolved (with higher hardness) or produced (with lower hardness), which leads to the phenomenon.

The dynamic recrystallization and grain refinement phenomenon can occur in the central stir zone during FSW $[14,15]$. Figure 2 a shows the microstructure between the TMAZ and the WN using metallographic analysis. Figures 2c,d show the TEM grain morphology in TMAZ and WN. The results indicate that the average grain size for TMAZ is about $2-4 \mu \mathrm{m}$, and the average grain size for $\mathrm{WN}$ is about $1-3 \mu \mathrm{m}$. 


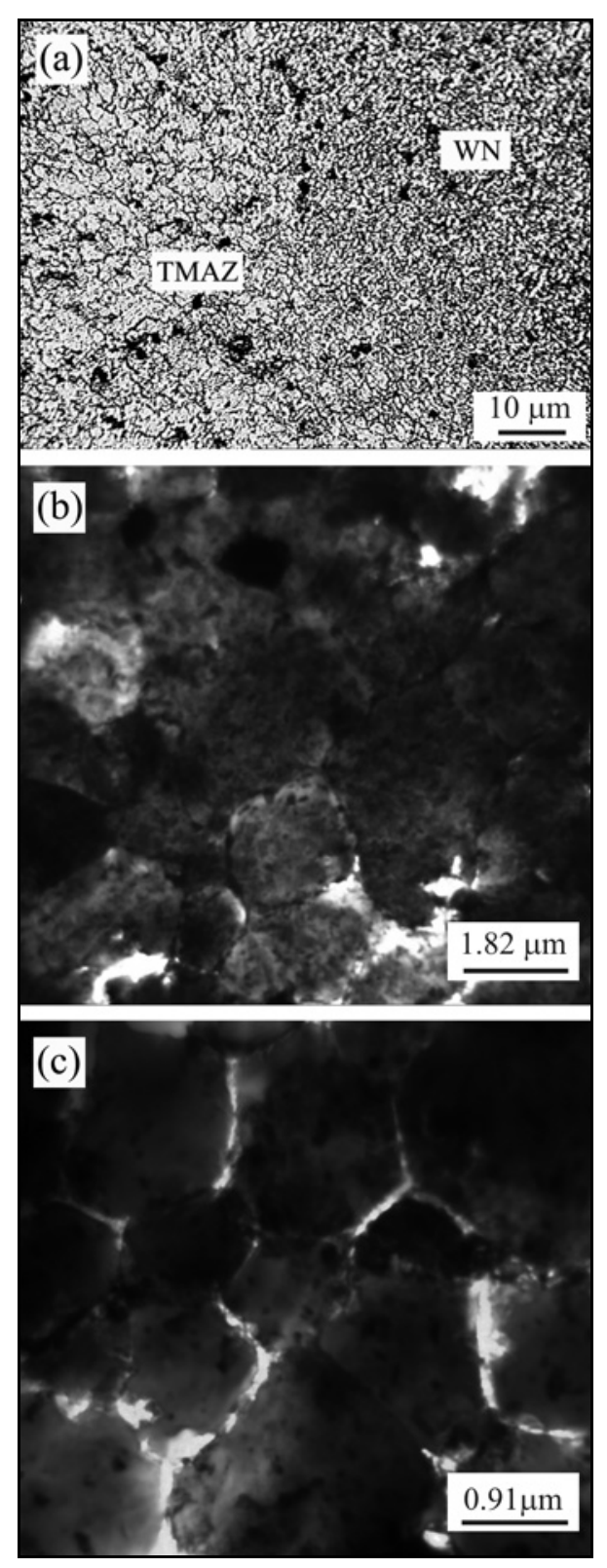

Fig. 2. Grain morphology in different weld regions: (a) microstructure between TMAZ and WN; (b) TMAZ and (c) $\mathrm{WN}$.

The grain size of TMAZ and WN was less than that of base metal (about $40 \mu \mathrm{m}$ ) [16]. The grain refinement of central stir zone is quite favourable to improve the performance of FSW joint.

\subsection{Precipitated phase analysis}

Precipitated phases in grain inner boundary and grain boundary of central weld were observed and analysed by TEM. Figure 3 shows the TEM morphology and corresponding electron diffraction pattern of precipitated phase in the WN. The TEM morphology and corresponding electron diffraction pattern of pre-
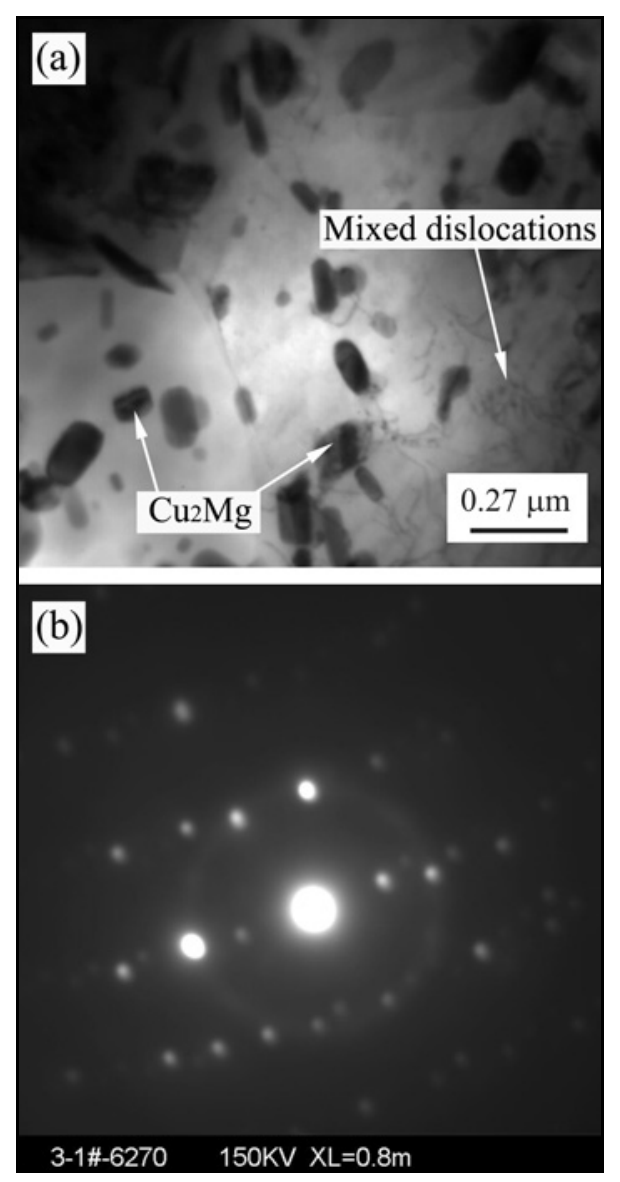

Fig. 3. TEM micrograph and corresponding electron diffraction pattern of the $\mathrm{Cu}_{2} \mathrm{Mg}$ [310] precipitated phase in the WN region: (a) TEM morphology; (b) electron diffraction pattern; (c) schematic index diagram of the panel (b).

cipitated phases in the TMAZ can be seen in Figs. 4 and 5 .

The results indicate that a large number of black granular precipitation particles $\left(\mathrm{Cu}_{2} \mathrm{Mg}\right)$ appeared in the WN region (see Fig. $3 \mathrm{a}$ ). The zone axis of $\mathrm{Cu}_{2} \mathrm{Mg}$ is $B=[310]$. The $\mathrm{Cu}_{2} \mathrm{Mg}$ has a face center cubic (fcc) structure, and lattice constant is $0.699 \mathrm{~nm}$ (see Figs. $3 \mathrm{~b}$ and $3 \mathrm{c}$ ). The $\mathrm{Cu}_{2} \mathrm{Mg}$ was mainly precipitated on the surface of the crystal grain, and little particles were precipitated near the grain boundary. The weld nugget (WN) region was subjected to a higher temperature during friction stir welding. Thus, dynamic recrystallization occurred here. With the effect of recrystallization and high temperature the $\mathrm{Cu}_{2} \mathrm{Mg}$ was precipitated. According to Fig. 3a, there are some complex mixed dislocations in the crystal grain. These dislocations may induce the internal stress in the WN region.

In the TMAZ, the precipitated phase is mainly Al-CuMg (U-phase) (see Fig. 4a). According to Figs. 4b and $4 \mathrm{c}$, the zone axis of $U(\mathrm{AlCuMg})$ is $B=[001]$. The 


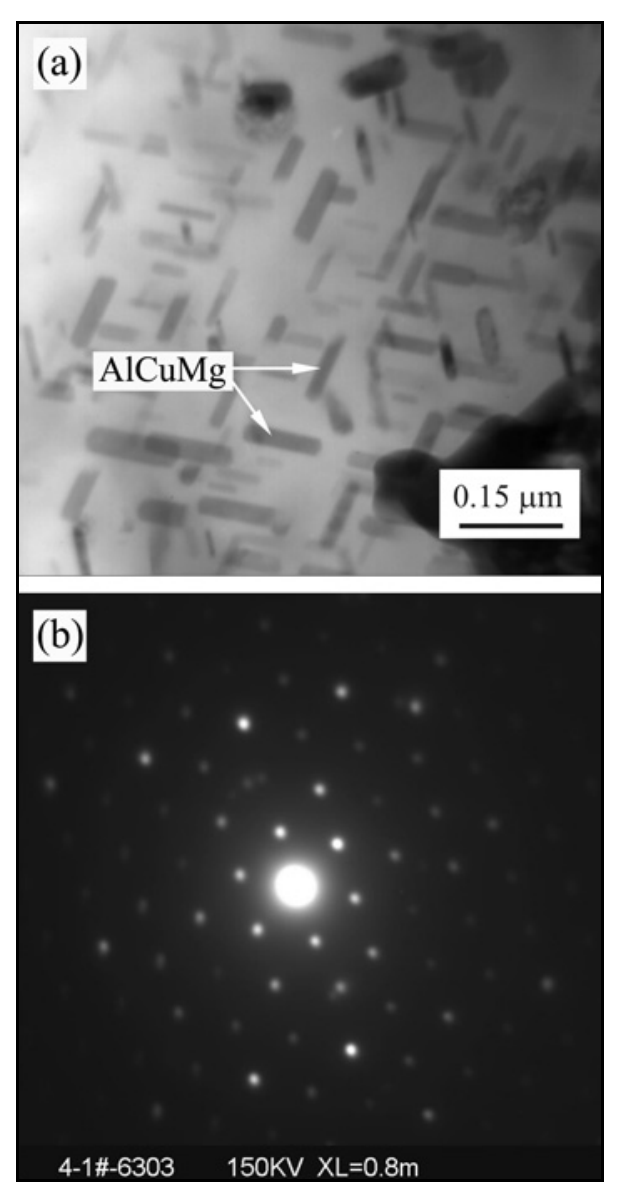

Fig. 4. TEM micrograph and corresponding electron diffraction pattern of the $\mathrm{AlCuMg}$ [001] precipitated phase in the TMAZ: (a) TEM morphology; (b) electron diffraction pattern; (c) schematic index diagram of the panel (b).

$\mathrm{AlCuMg}$ has a close-packed hexagonal (hcp) structure, and lattice constant is $0.509 \mathrm{~nm}$. In the Al-Cu-Mg alloys, the constituents that can exist in equilibrium with Al-rich solid solution are the two binary phases, $\mathrm{Mg}_{2} \mathrm{Al}_{3}$ ( $\beta$-phase) and $\mathrm{CuAl}_{2}$ ( $\theta$-phase). Moreover, the two ternary phases designated $S$ and $T$ are also reinforced phases [17]. At present, there is no report about $U$-phase observed in FSW joint of aluminium alloys. However, during FSW of 2024 aluminium alloys, the fine $S^{\prime}(S)$ precipitates were usually formed in the TMAZ. The $U$-phase formed in the TMAZ was not in equilibrium with aluminium-rich in the ternary alloys and was also a metastable phase [18].

The AlCuMg ( $U$-phase) found in the TMAZ region may be mainly related to the special FSW technology (such as stir tool, rotational/travel speed, temperature field, etc.). In FSW technology, the increase of temperature in TMAZ region induces the dissolution of GP zones $\left(\theta-\mathrm{CuAl}_{2}, \beta-\mathrm{Mg}_{2} \mathrm{Al}_{3}\right)$. Then, supersaturated solid solution continues precipitating: $\alpha \rightarrow$ GP zone $\rightarrow$ $U^{\prime} \rightarrow U(\mathrm{AlCuMg})$. The $\mathrm{AlCuMg}(U$-phase $)$ can be a metastable phase, and result in the internal stress in

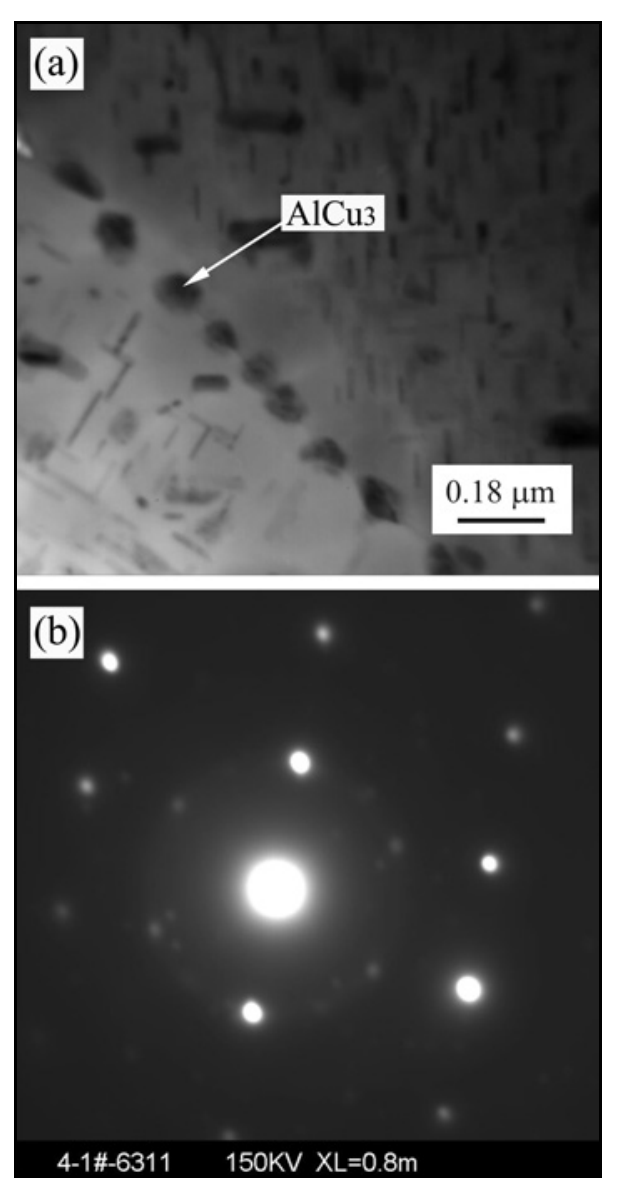

Fig. 5. TEM micrograph and corresponding electron diffraction pattern of the $\mathrm{AlCu}_{3}$ [111] precipitated phase and $\alpha-\mathrm{Al}$ [310] in the TMAZ: (a) TEM morphology; (b) electron diffraction pattern; (c) schematic index diagram of the panel (b).

the substrate. As a result, this phase can increase the strength of FSW 2024 weld. Moreover, the $U$-phase is likely to induce the formation of two distinct microhardness minima on HAZ/TMAZ and TMAZ/WN. However, further studies on the formation process of $\mathrm{AlCuMg}$ phase and the effect on FSW joint performance will be summarized in our next study.

Moreover, some of the black granular $\mathrm{AlCu}_{3}$ were aggregated and precipitated on the grain boundary of the TMAZ (see Fig. 5a). The zone axis of $\mathrm{AlCu}_{3}$ is $B=[111]$. The $\mathrm{AlCu}_{3}$ has a body-centred cubic (bcc) structure, and lattice constant is $0.295 \mathrm{~nm}$. The lattice orientation between $\mathrm{AlCu}_{3}$ and $\alpha$-Al is $(10 \overline{1})_{\mathrm{AlCu}_{3}} \|$ $(001)_{\alpha-\mathrm{Al}}$. The precipitated phase of $\mathrm{AlCu}_{3}$ gathering on the grain boundary may increase the brittleness of the FSW weld.

\section{Conclusions}

The 2024 aluminium alloy sheets in the T4 temper were welded successfully by friction stir welding. 
The average grain size for TMAZ is about $2-4 \mu \mathrm{m}$, and the average grain size for $\mathrm{WN}$ is about $1-3 \mu \mathrm{m}$ by TEM analysis. Grain refinement occurred in both WN and TMAZ. The AlCuMg ( $U$-phase) of metastable precipitates was found to exist in the TMAZ using TEM analysis. The AlCuMg has a close-packed hexagonal (hcp) structure, and lattice constant is $0.509 \mathrm{~nm}$. The $U$-phase is likely to induce the formation of two distinct microhardness minima on $\mathrm{HAZ} / \mathrm{TMAZ}$ and TMAZ/WN. The $\mathrm{AlCu}_{3}$ particles were aggregated and precipitated on the grain boundary of the TMAZ. The lattice orientation between $\mathrm{AlCu}_{3}$ and $\alpha$ $\mathrm{Al}$ is $(10 \overline{1})_{\mathrm{AlCu}_{3}} \|(001)_{\alpha-\mathrm{Al}}$. However, a large number of black granular precipitated particles, $\mathrm{Cu}_{2} \mathrm{Mg}$, appeared in the $\mathrm{WN}$ region.

\section{Acknowledgements}

This research was financially supported by the $\mathrm{Na}$ tional Natural Science Foundation of China (Grant No. 51305240) and the Science and Technology Projects of Colleges and Universities in Shandong Province (No. J15LA07)

\section{References}

[1] Metals Handbook. 9th Edition. Metals Park, ASM International 1979.

[2] Thomas, W. M., Nicholas, E. D., Needham, J. C., Murch, M. G., Temple-Smith, P., Dawes, C. J.: International Patent Application No. PCT/GB92/02203 and GB Patent Application No. 9125978.8. London, UK Patent Office 1991.

[3] Jeff, D.: Weld. J., 85, 2006, p. 42.

[4] Mahoney, M. W., Rhodes, C. G.: Metall. Mater. Trans. A, 28,1998 , p. 1955 . doi:10.1007/s11661-998-0021-5
[5] Sato, Y. S., Kokawa, H., Enomoto, M.: Metall. Mater. Trans. A, 30, 1999, p. 2429. doi:10.1007/s11661-999-0251-1

[6] Sutton, M. A., Yang, B., Reynolds, A. P., Taylor, R.: Mater. Sci. Eng. A, 323, 2002, p. 160. doi:10.1016/S0921-5093(01)01358-2

[7] Cabibbo, M., Meccia, E., Evangelista, E.: Mater. Chem. Phys., 81, 2003, p. 289. doi:10.1016/S0254-0584(02)00604-1

[8] Sato, Y. S., Park, S. H. C., Kokawa, H.: Metall. Mater. Trans. A, 32, 2001, p. 3033. doi:10.1007/s11661-001-0178-7

[9] Jones, M. J., Heurtier, P., Desrayaud, C., Montheilet, F., Allehaux, D., Driver, J. H.: Scripta Mater., 52, 2005, p. 693. doi:10.1016/j.scriptamat.2004.12.027

[10] Genevois, C., Deschamps, A., Denquin, A., DoisneauCottignies, B.: Acta Mater., 53, 2005, p. 2447. doi:10.1016/i.actamat.2005.02.007

[11] Genevois, C., Deschamps, A., Vacher, P.: Mater. Sci. Eng. A, 415, 2006, p. 162. doi:10.1016/i.msea.2005.09.032

[12] Frigaard, O., Grong, O., Milding, O. T.: Metall. Mater. Trans. A, 32, 2001, p. 1189. doi:10.1007/s11661-001-0128-4

[13] Denquin, A., Allehaux, D., Campagnac, M. H., Lapasset, G.: Mater. Sci. Forum, 426-432, 2003, p. 2921. doi:10.4028/www.scientific.net/MSF.426-432.2921

[14] Lityńska, L., Braun, R., Staniek, G., Dalle Donne, C., Dutkiewicz, J.: Mater. Chem. Phys., 81, 2003, p. 293. doi:10.1016/S0254-0584(02)00605-3

[15] Fonda, R. W., Bingert, J. F.: Metall. Mater. Trans. A, 37, 2006, p. 3593. doi:10.1007/s11661-006-1054-2

[16] Benavides, S., Li, Y., Murr, L. E., Brown, D., McClure, J. C.: Scripta Mater., 41, 1999, p. 809. doi:10.1016/S1359-6462(99)00226-2

[17] King, F.: Aluminium and its Alloys. Chichester, Ellis Horwood Ltd. 1987.

[18] Mondolfo, L. F.: Aluminium Alloys: Structure and Properties. London-Boston, Butterworths 1976. 